\title{
Inflammation and airway remodeling of the lung in guinea pigs with allergic rhinitis
}

\author{
ZU-YAO CHEN $^{1 *}$, SHOU-HONG ZHOU ${ }^{2 *}$, QIAO-FENG ZHOU ${ }^{3}$ and HONG-BO TANG ${ }^{1}$ \\ ${ }^{1}$ Department of Otorhinolaryngology, The First Affiliated Hospital; ${ }^{2}$ Institute of Neuroscience, School of Medicine;
${ }^{3}$ Department of Pediatrics, The First Affiliated Hospital, University of South China, Hengyang, Hunan 421001, P.R. China
}

Received October 7, 2016; Accepted June 1, 2017

DOI: $10.3892 /$ etm.2017.4937

\begin{abstract}
Allergic rhinitis (AR) and asthma belong to the category of type I allergic diseases, whose pathological features are airway remodeling of the lung and allergic inflammation. The aim of the present study was to evaluate inflammation and remodeling of lung tissue in a guinea pig model of AR in order to confirm consistent pathological changes of upper and lower airways in AR. Male guinea pigs were randomly divided into an experimental and a control group ( $n=10$ in each). The AR model was established by sensitization through intraperitoneal injection of ovalbumin for three weeks and bilateral nasal local excitation for twelve weeks. All tissues of nasal mucosa and lung were subjected to hematoxylin and eosin as well as toluidine blue staining, and characteristics of remodeling of lung tissue, including thickness of bronchial wall, epithelial mucosa and smooth muscle were histologically determined. Collagen deposition in lung tissue was observed by Masson's trichrome stain. Severe paroxysmal nose scratching action, frequent sneezing, visible outflow of secretion from the anterior naris and frequent nose friction were observed in the AR model group within $30 \mathrm{~min}$ after local excitation. The total symptom scores were significantly increased in the AR model group compared with those in the control group. Obvious inflammatory cell infiltration was observed in the AR model group. Compared with those in the control group, the numbers of eosinophils and mast cells in nasal mucosa and lung tissue were significantly increased. Obvious airway remodeling of the lung was observed in the AR model group. Compared with those in the control group, bronchial wall thickness, epithelial layer thickness and smooth muscle thickness in the
\end{abstract}

Correspondence to: $\mathrm{Mr}$. Zu-Yao Chen, Department of Otorhinolaryngology, The First Affiliated Hospital, University of South China, 69 Chuanshan Road, Hengyang, Hunan 421001, P.R. China

E-mail: chenzuyaohy@126.com

*Contributed equally

Key words: airway remodeling, lung, allergic rhinitis, inflammation, guinea pigs airways were significantly increased in the AR model group. Increased collagen deposition was found in the AR model group compared with that in the control group. The results of the present study revealed that inflammation and airway remodeling of lungs arose in guinea pigs with AR, suggesting that pathological changes of upper and lower airways are consistent in this AR model.

\section{Introduction}

Allergic rhinitis (AR) and asthma are common diseases with a high incidence rate and have a negative impact on the lives affected patients. AR and asthma used to be regarded as two different diseases, whose diagnosis and treatment were different (1). The AR and its impact on asthma (ARIA) initiative started during a workshop of the World Health Organization performed in 1999 and their guidelines were published in 2001 (2). Their review of 2010 provided guidelines for the diagnosis and treatment of AR and of clinical practices for the management of comorbidities of AR and asthma based on the Grading of Recommendations Assessment, Development and Evaluation method (3). ARIA has been popularized and implemented in $>50$ countries $(4,5)$. An increasing amount of research on 'airway consistency' has been performed, including epidemiology, pathology, clinical diagnosis and treatment (6).

AR and asthma belong to type I allergic diseases. It is currently thought that AR and asthma not only interact with each other but also are a risk factor for the development of the other diseases (7). Management of AR improves the symptoms of asthma. AR and asthma require an integrated management (8). Early diagnosis and aggressive treatment of AR or asthma may prevent the development of other diseases. Bronchial hyperreactivity (BHR) is a paramount feature of asthma and may be considered a strong risk factor for the onset of asthma in patients with AR. In a previous study, the bronchial methacholine test was performed in 342 patients with a moderate/severe degree of sustained AR. Of these, 22 (6.4\%) had severe BHR, 74 (21.6\%) had mild BHR and 192 (56.2\%) had borderline BHR (9). Buslau et al (10) found that most patients with AR exhibited signs of BHR, and that $30 \%$ of patients with AR may develop asthma later in life. Andiappan et al (11) found that neuropeptide $\mathrm{S}$ receptor 1 and cytotoxic $\mathrm{T}$ lymphocyte-associated antigen- 4 were the genetic links between AR and asthma, indicating the presence of a certain genetic consistency among the 
pathogeneses of the two diseases. The present study indicated that ongoing AR was associated with worsening of asthma by enhancing lower airway inflammation in patients with atopy (12). Chawes (13) also found that the nasal pathology in young children with allergic and non-allergic rhinitis exhibited marked differences, suggesting close association between upper and lower airway diseases partly through an allergy-driven process, but equally via non-allergic mechanisms. Regarding the effects of the pathogenetic process of AR on lung airway remodeling in patients with AR, only few studies have assessed this possible association $(14,15)$.

Wagener et al (16) identified 1988 differentially expressed genes between healthy lower and upper airway epithelium, whereas only 40 and 301 genes were differentially expressed in AR with or without asthma, respectively. These results suggested that genes affected by AR with or without asthma may be associated with lung development and remodeling as well as normal epithelial barrier functions and regulation of peptidases. Airway remodeling of the lung and allergic inflammation are the pathological features of asthma. Lower airway inflammation and remodeling during the course of the pathogenesis of AR remain to be fully demonstrated. Therefore, the present study was designed to evaluate the inflammation and airway remodeling of lung tissue in a guinea pig model of AR.

\section{Materials and methods}

Animals. A total of 20 healthy male guinea pigs (weight, 150-220 g; age, 5-6 months) were obtained from the experimental animal center of the University of South China (Hengyang, China). The humidity of the rearing environment was $50 \pm 5 \%$ and the ambient temperature was $22.5 \pm 2.5^{\circ} \mathrm{C}$. The guinea pigs were housed under a 12-h light/dark cycle with free access to water and food. The animal experiments were approved by the Committee on the Ethics of Animal Experiments of the University of South China (Hengyang, China). All efforts were made to minimize the number of animals and their suffering.

Animal grouping and induction of AR animal models. The guinea pigs were randomly divided into a normal control group and an AR model group. The animals were allowed to adapt to the experimental environment for one week. The AR model was established according a previous method (17). In brief, the guinea pigs were administered a suspension of $0.3 \mathrm{mg}$ ovalbumin (OVA) and $30 \mathrm{mg}$ aluminum hydroxide (both from Sigma-Aldrich; Merck KGaA, Darmstadt, Germany) in $1 \mathrm{ml}$ normal saline by intraperitoneal injection every other day for a total of 7 times. Furthermore, in order to induce local excitation, $50 \mu 12 \%$ OVA solution was dripped into each side of the nasal cavity of the guinea pigs once a day for twelve weeks. The guinea pigs in the normal control group were treated with the same amount of normal saline. Behavioral symptom scores were evaluated and recorded.

Standard for evaluation of nasal symptoms. Each local nasal excitation in guinea pigs was observed and recorded, including scratching nose action, frequency of sneezing and condition of the nose. Nasal symptoms were evaluated according to the standard scoring system presented in Table I. The total score
Table I. Standard for evaluation of nasal symptoms.

\begin{tabular}{llcl}
\hline $\begin{array}{l}\text { Symptoms } \\
\text { score }\end{array}$ & $\begin{array}{c}\text { Scratching } \\
\text { nose action }\end{array}$ & $\begin{array}{c}\text { Frequency } \\
\text { of continuous } \\
\text { sneezing }\end{array}$ & \multicolumn{1}{c}{$\begin{array}{c}\text { Condition } \\
\text { of nose }\end{array}$} \\
\hline 0 & None & 0 & Normal \\
1 & Light touch & $1-3$ & Flow to the nostrils \\
2 & Strong & $4-10$ & Flow beyond the \\
& scratching & & nostril \\
3 & Full rubbing & $>11$ & Flow to the lips \\
\hline
\end{tabular}

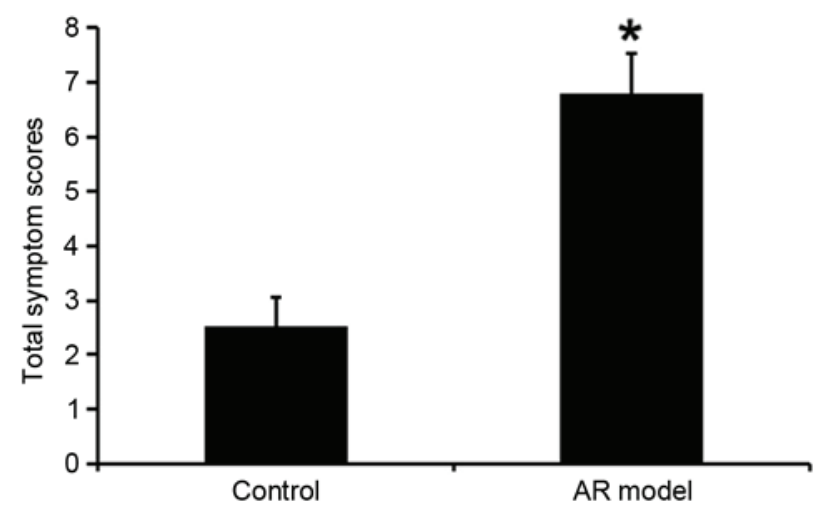

Figure 1. Total symptom scores in guinea pigs with AR. AR was induced by ovalbumin challenge. The nasal symptoms were evaluated according to scoring criteria listed in Table I. Values are expressed as the mean \pm standard deviation ( $\mathrm{n}=10$ per group). ${ }^{*} \mathrm{P}<0.05$ compared with the control group. AR, allergic rhinitis.

was recorded and a total score of $>5$ points indicated the successful establishment of the AR model in the guinea pigs.

Preparation of nasal mucosa and lung tissues and histological analysis. The guinea pigs were deeply anesthetized with $10 \%$ chloral hydrate solution $(300 \mathrm{mg} / \mathrm{kg}$; Sigma-Aldrich; Merck $\mathrm{KGaA}$ ) by intraperitoneal injection. The nasal bone of each guinea pig was removed and the nasal mucosa was gained. The lung was removed. Nasal mucosa and lung tissues were fixed in $4 \%$ paraformaldehyde at $4^{\circ} \mathrm{C}$ for $48 \mathrm{~h}$. Nasal mucosa was decalcified in $10 \%$ EDTA (Sigma-Aldrich; Merck KGaA). The tissues were embedded in paraffin and sliced at a thickness of 4-5 $\mu \mathrm{m}$. The sections were stained with hematoxylin and eosin $(\mathrm{H} \& \mathrm{E})$ or toluidine blue (Sigma-Aldrich; Merck KGaA). Collagen deposition in lung tissues was observed by Masson's trichrome stain. Five microscopic fields were randomly selected, and the eosinophils and mast cells in each high-power microscopic field (magnification, x400) were counted under a light microscope.

Analysis of airway remodeling in lung tissue. Image analysis software Image Pro Plus V6 (Media Cybernetics, Inc., Rockville, MD, USA) was utilized to measure the circumference of the bronchial basement membrane, total area of bronchia, total area of bronchial lumen, area of the bronchia within the outer or inner edge of the epithelial layer and area of the bronchia within the outer or inner edge of the smooth muscle of lung tissue sections after H\&E staining. The thickness 
A
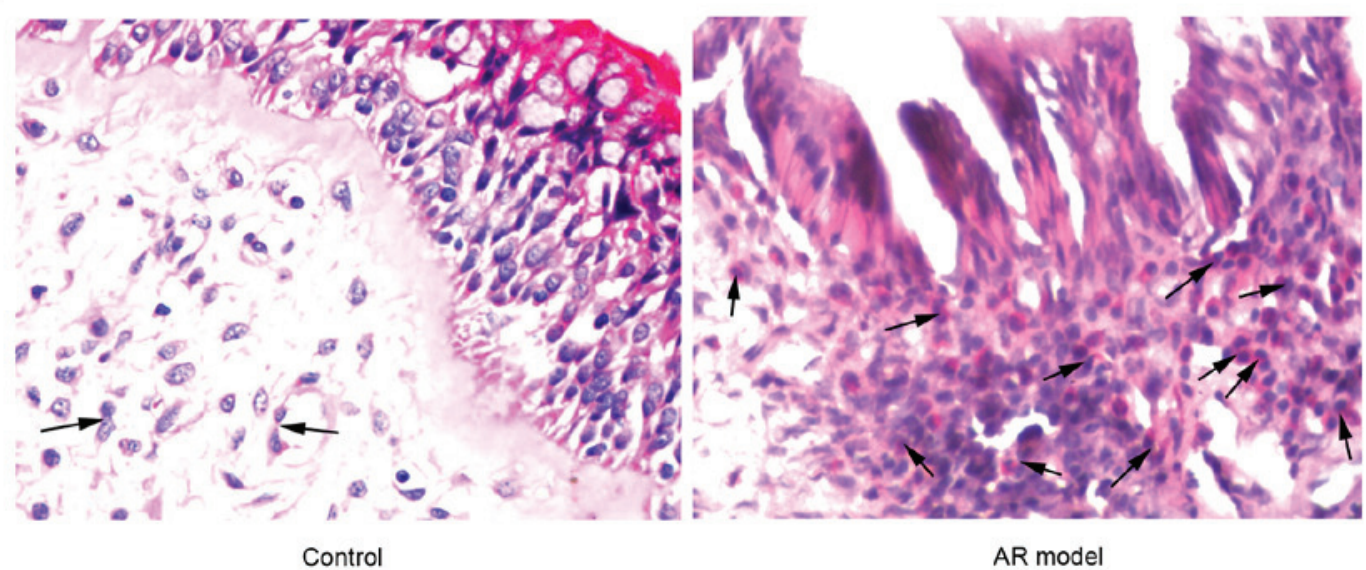

B

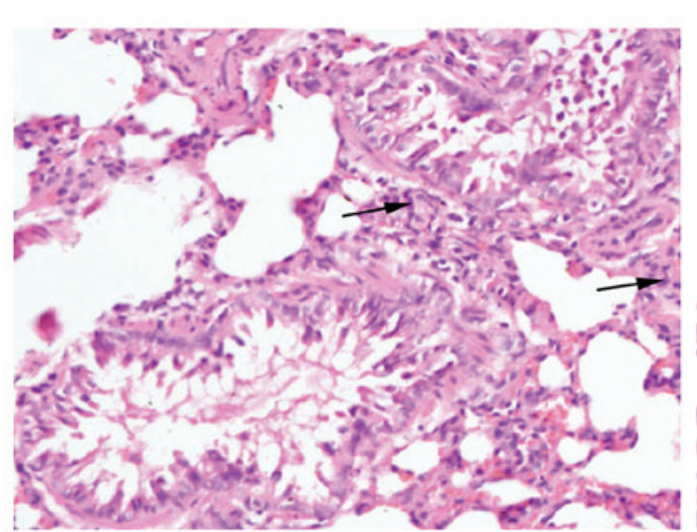

Control

C

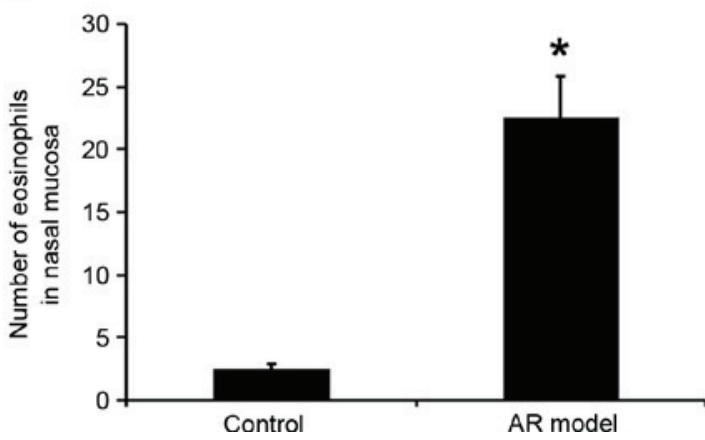

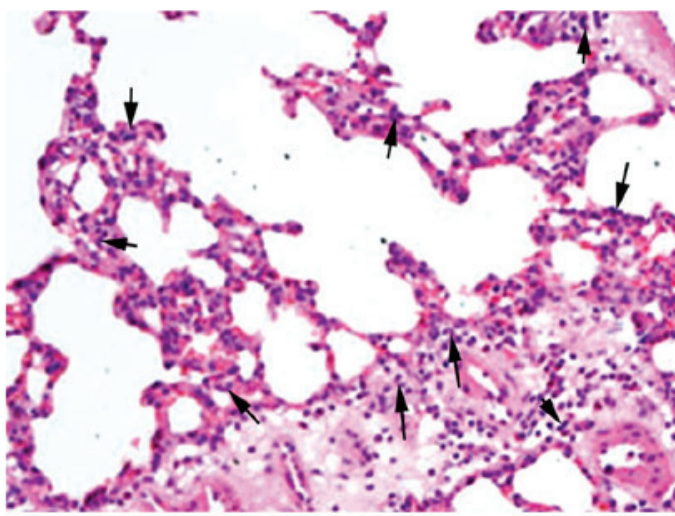

AR model

D

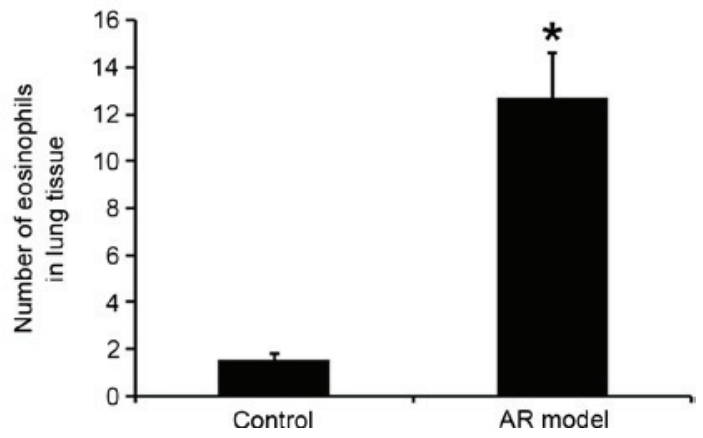

Figure 2. Infiltration of eosinophils in nasal mucosa and lung tissue of guinea pigs with AR. AR was induced by ovalbumin challenge. Histological images of (A) nasal mucosa and (B) lung tissue (hematoxylin and eosin stain; magnification, x400). The arrows indicate eosinophils. The numbers of eosinophils per high-power field in (C) nasal mucosa and (D) lung tissue were counted. Values are expressed as the mean \pm standard deviation ( $\mathrm{n}=10$ per group). ${ }^{*} \mathrm{P}<0.05$ compared with the control group. AR, allergic rhinitis.

of the bronchial wall, epithelial layer and bronchial smooth muscle was then calculated as characteristics of airway remodeling. The parameters were calculated as follows: Bronchial wall thickness $=($ total area of bronchia-total area of bronchial lumen)/bronchial basement membrane size. Epithelial layer thickness $=($ area of the bronchia within the outer edge of the epithelial layer-area of the bronchia within the inner edge of the epithelial layer)/bronchial basement membrane diameter. Bronchial smooth muscle thickness $=$ (area of the bronchia within the outer edge of the smooth muscle-area of the bronchia within the inner edge of the smooth muscle)/bronchial basement membrane diameter.
Statistical analysis. Values are expressed as the mean \pm standard deviation. Differences between groups were analyzed using the Student's t-test. All statistical analyses were performed by using SPSS 17.0 statistical software (SPSS, Inc., Chicago, IL, USA). $\mathrm{P}<0.05$ was considered to indicate a statistically significant difference.

\section{Results}

Nasal symptoms and total symptom scores in guinea pigs with $A R$. Nasal symptoms such as severe paroxysmal nose scratching action, frequent sneezing, visible outflow of 
A

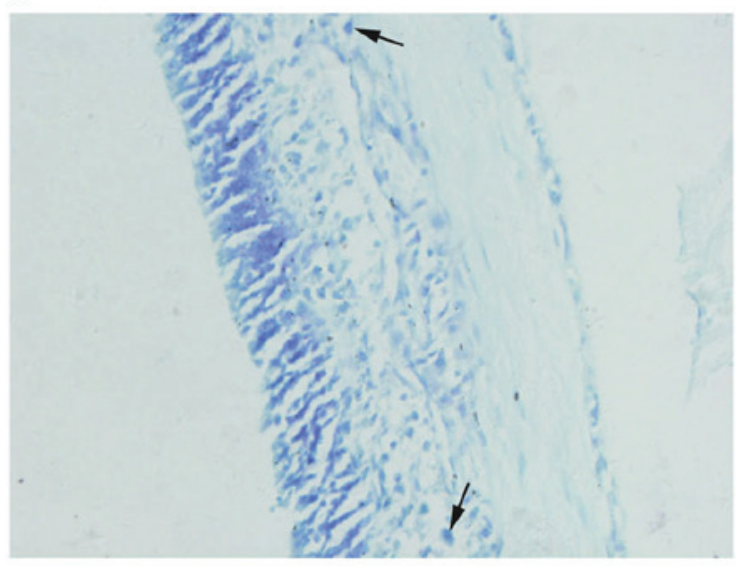

Control

B

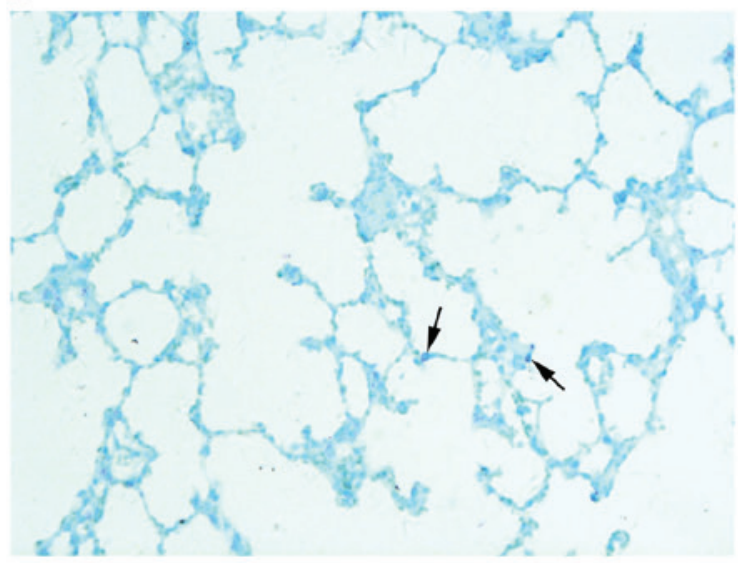

Control

C

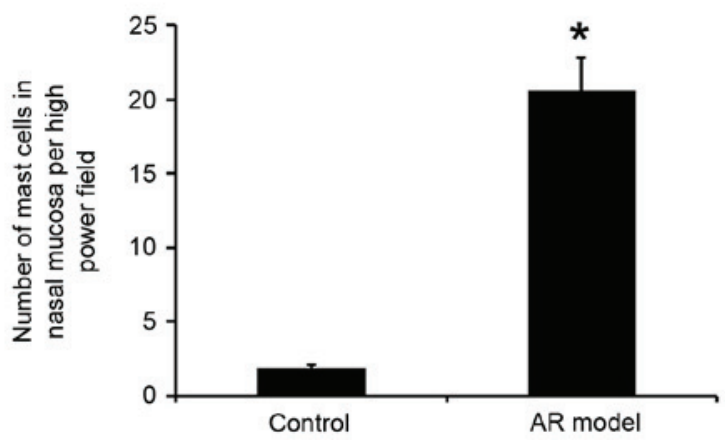

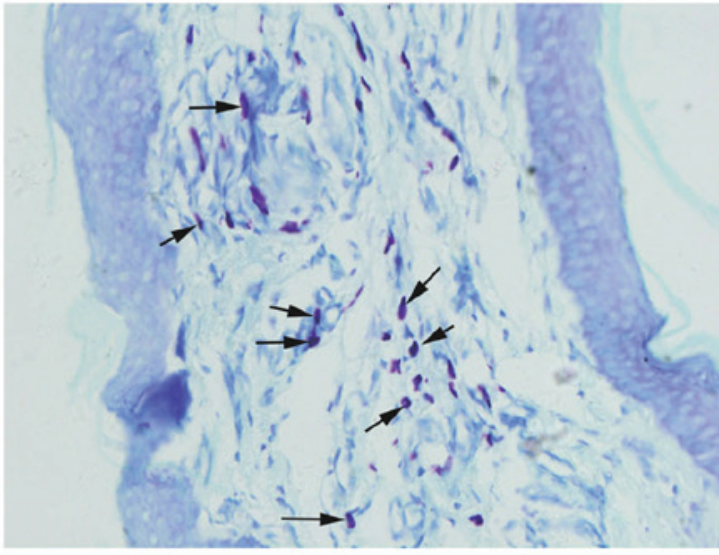

AR model

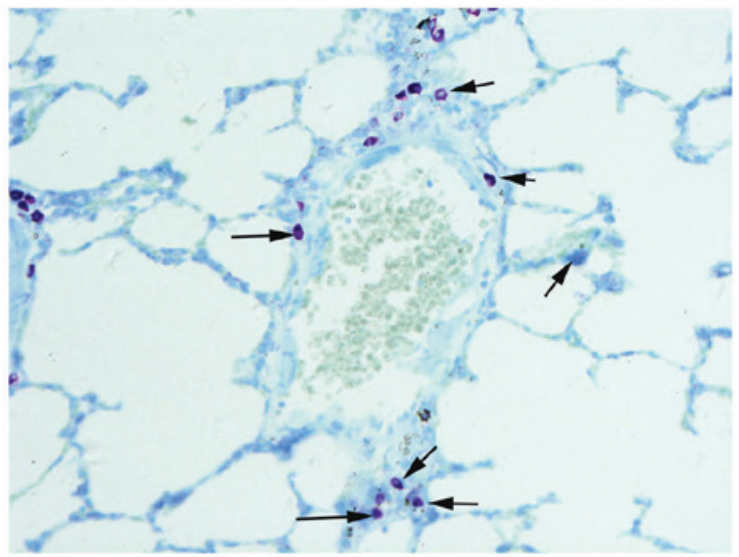

AR model

D

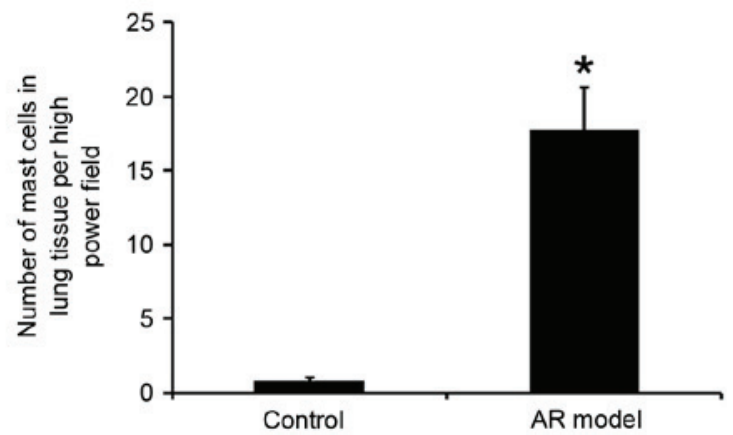

Figure 3. Infiltration of mast cells in nasal mucosa and lung tissue of guinea pigs with AR. AR was induced by ovalbumin challenge. Histological analysis of (A) nasal mucosa and (B) lung tissue was performed by toluidine blue staining (magnification, $\mathrm{x} 400$ ). The arrows indicate mast cells. The numbers of mast cells per high-power field in (C) nasal mucosa and (D) lung tissue were counted. Values are expressed as the mean \pm standard deviation ( $\mathrm{n}=10$ per group). ${ }^{*} \mathrm{P}<0.05$ compared with the control group. AR, allergic rhinitis.

secreta from the anterior naris and frequent nose friction were observed in the AR model group within 30 min after local excitation. The guinea pigs in the AR model group refrained from eating and drinking, and cried within $2 \mathrm{~h}$ after local excitation. The total symptom scores were significantly increased in the AR model group compared with those in the control group (Fig. 1).

Inflammatory cell infiltration in nasal mucosa and lung tissues. As presented in Figs. 2 and 3, obvious inflammatory cell infiltration in the nasal mucosa and lung tissues was observed in the AR model group. Compared with those in the control group, the numbers of eosinophils and mast cells in the nasal mucosa and lung tissues were significantly increased (all $\mathrm{P}<0.05)$.

Airway remodeling in lung tissues. As displayed in Fig. 4 and Table II, obvious airway remodeling of lung tissues was observed in the AR model group. Compared with that in the control group, the thickness of bronchial wall, epithelial layer 
Table II. Airway remodeling of lung tissue in guinea pigs with AR.

\begin{tabular}{lcccc}
\hline Group & $\mathrm{n}$ & $\begin{array}{c}\text { Bronchial } \\
\text { wall } \\
\text { thickness } \\
\left(\mu \mathrm{m}^{2} / \mu \mathrm{m}\right)\end{array}$ & $\begin{array}{c}\text { Epithelial } \\
\text { layer } \\
\text { thickness } \\
\left(\mu \mathrm{m}^{2} / \mu \mathrm{m}\right)\end{array}$ & $\begin{array}{c}\text { Smooth } \\
\text { muscle } \\
\text { thickness } \\
\left(\mu \mathrm{m}^{2} / \mu \mathrm{m}\right)\end{array}$ \\
\hline Control & 10 & $16.60 \pm 1.00$ & $11.44 \pm 0.87$ & $4.15 \pm 0.30$ \\
AR model & 10 & $18.82 \pm 0.91$ & $13.52 \pm 1.10$ & $6.19 \pm 0.78$ \\
\hline
\end{tabular}

$\mathrm{AR}$, allergic rhinitis.
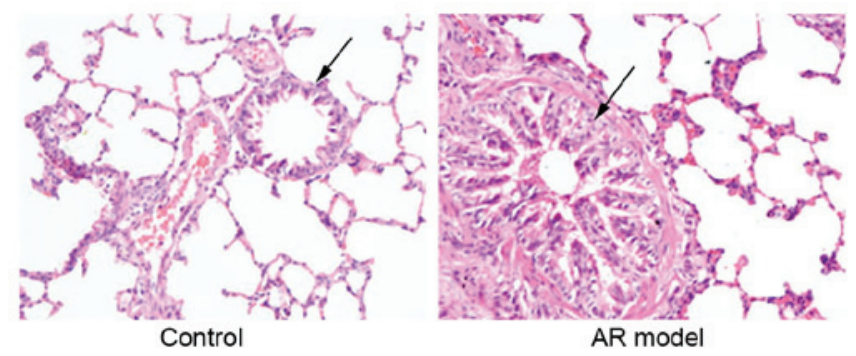

Figure 4. Airway remodeling of lung tissue in guinea pigs with AR AR was induced by ovalbumin challenge. Histological analysis of lung tissue was performed by hematoxylin and eosin staining (magnification, $\mathrm{x} 400$ ). The arrows indicate the bronchioles. The thickness of the bronchial wall, epithelial layer and smooth muscle in the airways of the AR model group was observed to be increased compared with that in the control group. $\mathrm{AR}$, allergic rhinitis.

and smooth muscle in the airways were significantly increased in the AR model group $(\mathrm{P}<0.05)$. Compared with that in the control group, more collagen deposition was found in the AR model group (Fig. 5).

\section{Discussion}

Airway remodeling leads to reversible airflow obstruction and persistent airway hyperresponsiveness, and is also an important feature of asthma in addition to chronic airway inflammation (18). Airway remodeling directly affects the outcome of asthma. It refers to the pathological changes of the airway, which include airway epithelial injury, epithelial fibrosis, hypertrophy, proliferation and migration of airway smooth muscle (ASM), an increased number of activated and muscle fibroblasts, goblet cell proliferation, mucus secretion, angiogenesis, decreased cartilage integrity and increased airway vascularity (19). Numerous types of inflammatory cell, including eosinophils, T lymphocytes, macrophages, mast cells and neutrophils, as well as airway structural cells, including ASM cells, epithelial cells and fibroblasts, release a variety of cytokines, including chemokines, growth factors and extracellular matrix protein. A variety of cytokines form a complex signaling environment participating in and strengthening airway remodeling (20). In a mouse model of chronic asthma, Stellari et al (21) confirmed that metalloproteinase was significantly increased at 8 and 11 weeks, which coincided with hypertrophy of the airway epithelium and with collagen

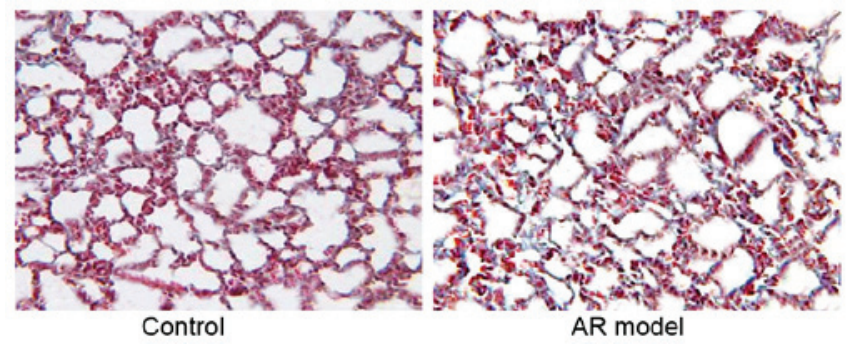

Figure 5. Collagen deposition in lung tissue of guinea pigs with AR AR was induced by ovalbumin challenge. Collagen deposition in lung tissue was observed by Masson's trichrome stain (magnification, x400). The results demonstrated that more collagen deposition was present in the AR model group compared with that in the control group. AR, allergic rhinitis.

deposition, as histologically evaluated by Masson's trichrome staining. Increases in blood vessel density and vascular area are now recognized as important features of remodeled airways in asthma. In a sheep model of chronic asthma, van der Van der Velden et al (22) found that blood vessel density and the percentage of airway vascularity in the bronchi were significantly increased following 24 weeks of house dust mite challenge compared with those in untreated controls. Fibrosis is also one of the key pathological features of airway remodeling in asthma. In normal airways, the amount of collagen and other extracellular matrix components is maintained in equilibrium by regulation of synthesis and degradation. In asthma, this homeostasis is disrupted due to genetic and environmental factors (9). Airway remodeling contributes to the thickening of airway walls and consequently leads to airway narrowing.

Allergen challenge of the nose induces the influx of inflammatory cells in the lower airways and vice versa. Treatment of the nose, in various ways, is likely to affect inflammation in the lower airways (12). In a study by Hovland et al (23), BHR was assessed by metacholine bronchial challenge, and airway inflammation was assessed by fractional exhaled nitric oxide (FeNO), revealing that boys with asthma and AR had significantly more severe BHR and higher FeNO than those with other asthma phenotypes. Kim et al (24) evaluated 3 characteristics in AR using measurement of FeNO, a methacholine challenge test and impulse oscillometry (IOS), and found reversible lower airway obstruction on IOS and elevated FeNO levels in children with AR. Elevated FeNO levels indicated airway inflammation, suggesting that chronic inflammation may lead to BHR in AR. Chawes (13) confirmed that BHR was increased and the level of FeNO was elevated in children with AR, suggesting different endotypes of asthma symptoms in young children with allergic- and non-allergic rhinitis. They also found bronchial hyperresponsiveness and increased values of FeNO in children with AR without asthma, suggesting sub-clinical bronchial inflammation and supporting that the allergic disease process involves the upper as well as lower airways. An experimental study by Bonay et al (25) suggested that eosinophils participate in bronchial inflammation in patients with seasonal AR following allergic nasal challenge outside the pollen season and may result in airway responsiveness. In conclusion, the abovementioned studies objectively demonstrated that the nasal pathology in AR may have an important role in inflammation and BHR of the lower 
airways. However, it remains to be fully demonstrated whether AR affects the remodeling of lung tissue.

The present study revealed obvious inflammation, including infiltration of eosinophils and mast cells in the upper and lower airway tissues of guinea pigs with AR, which indicated airway inflammation consistency. The remodeling of lung tissues in guinea pigs with AR was evaluated by measuring the thickness of the bronchial wall, epithelial mucosa and smooth muscle, which changed during the pathogenesis of asthma. Remodeling of lung tissue of guinea pigs was observed after twelve weeks of local ovalbumin excitation and more collagen deposition was found in the AR model group compared with that in the control group. The process of local excitation represents an AR attack. The present study indicated that repeated attacks of AR may lead to the occurrence of pulmonary airway remodeling in guinea pigs with AR. The integrity of the upper and lower airways in this process was therefore indicated. The mechanisms underlying the consistency of upper and lower airway pathology in guinea pigs with AR requires further study.

\section{References}

1. Amaral R, Carneiro AC, Wandalsen G, Fonseca JA and Sole D: Ann Control of Allergic Rhinitis and Asthma Test for Children (CARATKids): Validation in Brazil and cutoff values. Ann Allergy Asthma Immunol 118: 551-556. e2, 2017.

2. Bousquet J, Van Cauwenberge P and Khaltaev N; Aria Workshop Group; World Health Organization: Allergic rhinitis and its impact on asthma. J Allergy Clin Immunol 108 (5 Suppl): S147-S334, 2001

3. Brozek JL, Bousquet J, Baena-Cagnani CE, Bonini S, Canonica GW, Casale TB, van Wijk RG, Ohta K, Zuberbier T, Schünemann HJ, et al: Allergic Rhinitis and its Impact on Asthma (ARIA) guidelines: 2010 revision. J Allergy Clin Immunol 126 : 466-476, 2010.

4. Provost D, Iwatsubo Y, Riviere S, Mevel M, Didier A, Brochard P, Imbernon $\mathrm{E}$ and Raherison $\mathrm{C}$ : The impact of allergic rhinitis on the management of asthma in a working population. BMC Pulm Med 15: 142, 2015.

5. Sahay S, Gera K, Bhargava SK and Shah A: Occurrence and impact of sinusitis in patients with asthma and/or allergic rhinitis. J Asthma 53: 635-643, 2016.

6. Van der Leeuw S, Van der Molen T, Dekhuijzen PN, Fonseca JA, van Gemert FA, Gerth van Wijk R, Kocks JW, Oosterom H, Riemersma RA, Tsiligianni IG, et al: The minimal clinically important difference of the Control of Allergic Rhinitis and Asthma Test (CARAT): Cross-cultural validation and relation with pollen counts. NPJ Prim Care Respir Med 25: 14107, 2015.

7. Schmitt J, Schwarz K, Stadler E and Wüstenberg EG: Allergy immunotherapy for allergic rhinitis effectively prevents asthma: Results from a large retrospective cohort study. J Allergy Clin Immunol 136: 1511-1516, 2015.

8. Camargos P, Ibiapina C, Lasmar L and Cruz AA: Allergic rhinitis and asthma require an integrated management. Thorax 67: 1014 2012.
9. Royce SG, Cheng V, Samuel CS and Tang ML: The regulation of fibrosis in airway remodeling in asthma. Mol Cell Endocrinol 351: 167-175, 2012.

10. Buslau A, Voss S, Herrmann E, Schubert R, Zielen S and Schulze J: Can we predict allergen-induced asthma in patients with allergic rhinitis? Clin Exp Allergy 44: 1494-1502, 2014.

11. Andiappan AK, Nilsson D, Halldén C, Yun WD, Säll T, Cardell LO and Tim CF: Investigating highly replicated asthma genes as candidate genes for allergic rhinitis. BMC Med Genet 14: 51, 2013.

12. Mehta P: Allergic rhinitis and bronchial asthma. J Assoc Physicians India 62 (3 Suppl): S23-S26, 2014.

13. Chawes BL: Upper and lower airway pathology in young children with allergic- and non-allergic rhinitis. Dan Med Bull 58: B4278, 2011.

14. Eifan AO, Orban NT, Jacobson MR and Durham SR: Severe persistent allergic rhinitis. Inflammation but no histologic features of structural upper airway remodeling. Am J Respir Crit Care Med 192: 1431-1439, 2015.

15. Lim YS, Won TB, Shim WS, Kim YM, Kim JW, Lee CH, Min YG and Rhee CS: Induction of airway remodeling of nasal mucosa by repetitive allergen challenge in a murine model of allergic rhinitis. Ann Allergy Asthma Immunol 98: 22-31, 2007.

16. Wagener AH, Zwinderman AH, Luiten S, Fokkens WJ, Bel EH, Sterk PJ and van Drunen CM: The impact of allergic rhinitis and asthma on human nasal and bronchial epithelial gene expression. PLoS One 8: e80257, 2013.

17. AI Suleimani YM, Dong Y and Walker MJ: Differential responses to various classes of drugs in a model of allergic rhinitis in guinea pigs. Pulm Pharmacol Ther 21: 340-348, 2008.

18. Girodet PO, Dournes G, Thumerel M, Begueret H, Dos Santos P, Ozier A, Dupin I, Trian T, Montaudon M, Laurent F, et al: Calcium channel blocker reduces airway remodeling in severe asthma. A proof-of-concept study. Am J Respir Crit Care Med 191: 876-883, 2015.

19. Gras D, Bourdin A, Chanez P and Vachier I: Airway remodeling in asthma: Clinical and functional correlates. Med Sci (Paris) 27: 959-965, 2011 (In French).

20. Shimizu S, Kouzaki H, Ogawa T, Takezawa K, Tojima I and Shimizu T: Eosinophil-epithelial cell interactions stimulate the production of MUC5AC mucin and profibrotic cytokines involved in airway tissue remodeling. Am J Rhinol Allergy 28: 103-109, 2014.

21. Stellari F, Sala A, Ruscitti F, Carnini C, Mirandola P, Vitale M, Civelli $\mathrm{M}$ and Villetti G: Monitoring inflammation and airway remodeling by fluorescence molecular tomography in a chronic asthma model. J Transl Med 13: 336, 2015.

22. Van der Velden J, Barker D, Barcham G, Koumoundouros E and Snibson K: Increased vascular density is a persistent feature of airway remodeling in a sheep model of chronic asthma. Exp Lung Res 38: 307-315, 2012.

23. Hovland V, Riiser A, Mowinckel P, Carlsen KH and Carlsen KC: Asthma with allergic comorbidities in adolescence is associated with bronchial responsiveness and airways inflammation. Pediatr Allergy Immunol 25: 351-359, 2014.

24. Kim YH, Park HB, Kim MJ, Kim HS, Lee HS, Han YK, Kim KW, Sohn MH and Kim KE: Fractional exhaled nitric oxide and impulse oscillometry in children with allergic rhinitis. Allergy Asthma Immunol Res 6: 27-32, 2014.

25. Bonay M, Neukirch C, Grandsaigne M, Leçon-Malas V, Ravaud P, Dehoux M and Aubier M: Changes in airway inflammation following nasal allergic challenge in patients with seasonal rhinitis. Allergy 61: 111-118, 2006. 